\title{
Repositórios Institucionais e Objetos Virtuais de Aprendizagem
}

\author{
Relatório do evento realizado pela Biblioteca Central, pela \\ Coordenação da Universidade Aberta do Brasil e pelo Programa \\ de Pós-Graduação em Ciência da Informação da Universidade \\ Federal de Santa Catarina.
}

Florianópolis, 4, 5 e 6 de novembro de 2009.

Rosângela Schwarz Rodrigues

Profa. no Programa de Pós-graduação em Ciência da Informação UFSC

e-mail: $\underline{\text { rosangela@ } @ \text { cin.ufsc.br }}$

O evento "Repositórios Institucionais e Objetos Virtuais de Aprendizagem", ocorrido nos dias 4, 5 e 6 de novembro de 2009 foi um marco em relação às discussões sobre o referido tema na Universidade Federal de Santa Catarina (UFSC). Organizado pela Biblioteca Central, com o apoio da coordenação da Universidade Aberta do Brasil, da Pró-Reitoria de Graduação e do Programa de Pós-Graduação em Ciência da Informação da UFSC, a abertura do evento contou com a presença do professor Carlos Alberto Justos da Silva, vice-reitor da UFSC (representando o reitor); da professora Maria Lúcia de Camargo, pró-reitora de Pós-Graduação; do diretor de ensino da Pró-reitoria de Assuntos Estudantis, professor Carlos Pinto; da coordenadora da Universidade Aberta do Brasil na UFSC, professora Eleonora Milano Falcão Vieira e da diretora da Biblioteca Central, Narcisa Amboni. O encontro reuniu dezesseis especialistas que apresentaram trabalhos e participaram de discussões com professores, servidores técnico-administrativos e estudantes.

Os palestrantes concordaram gentilmente em disponibilizar suas apresentações, que organizamos nesta edição da Encontros Bibli para garantir a visibilidade e segurança. A seguir um breve resumo dos trabalhos apresentados:

Adi Balbinot Junior (Coordenação Geral de Política de Tecnologia da Informação CGTI/DED/CAPES) apresentou dados e projeções da Universidade Aberta do Brasil, que indicam que em 2013 teremos 800.000 alunos a distância em 1.000 polos. Nesse sentido também, teremos mais de 520 cursos (graduação e pós-graduação); mais de 30.000 disciplinas e mais de 2.500 colaboradores. Destacou-se as perspectivas de implantação do SISUAB, o repositório para a UAB, integrado com os Ambientes Virtuais de Ensino e Aprendizagem e com padrões internacionais de metadados para bibliotecas digitais (SCORM, LOM, Dublin Core).

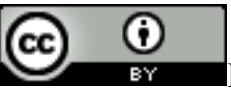
DOI 10.5007/1518-2924.2010v15n29p209

Enc. Bibli: R. Eletr. Bibliotecon. Ci. Inf., ISSN 1518-2924, Florianópolis, v. 15, n. 29, p.209-211, 2010. 
Adriane Borba Almeida da Silva (professora da Universidade Federal de Pelotas) apresentou relato de experiência na (des) organização e compartilhamento de materiais didáticos digitais, onde destacou questões relacionadas ao uso compartilhado pelo presencial, objetos gráficos sofisticados em animações e formação de equipes para gestão.

Anna Christina de Azevedo Nascimento (Secretaria de Educação a Distância do Ministério da Educação) apresentou o Banco Internacional de Objetos Educacionais, destacando questões relacionadas com o material selecionado por comitê editorial, projeto de interoperabilidade com os outros sistemas do Ministério da Educação (Portal, Domínio público, e-proinfo).

Carmem Lucia Prata (do Portal do Professor do MEC) apresentou vários projetos voltados para professores em todos os níveis com materiais educacionais em diferentes suportes. Destacou a possibilidades de postar comentários e relatos de experiências.

Eloy Rodrigues (Diretor dos Serviços de Documentação da Universidade do Minho) destacou as políticas de acesso livre das instituições com base no Scientific Council of the European Research Council, que define uma política obrigatória de auto-arquivo em acesso livre. A expansão da visibilidade das publicações foi exponencial, colocando a universidade do Minho em $1^{\circ}$ lugar no ranking web. Discursou sobre a importância das diretrizes e formas para garantir a interoperabilidade e compatibilidade com os serviços, e ressaltou para que os programadores de plataformas de repositórios incorporem novas funcionalidades em futuras versões. O Projecto Open Access Infrastructure for Research in Europe trabalha na infraestrutura e mecanismos de suporte para o depósito, identificação, acesso e monitorização dos artigos financiados.

Liane Tarouco (professora da Universidade Federal do Rio Grande do Sul) destacou a variedade e volatilidade dos AVAs, a necessidade de repositórios confiáveis para recuperar objetos a longo prazo. Necessidade de atribuição de status dos usuários. Interoperabilidade e adoção de padrões IMS, AICC, IEEE (LTSC), ARIADNE. Gerenciamento de conteúdos e buscas de acordo com os padrões do JISC e associados. Narrou sobre federação de repositórios, projeto ARCA na Espanha e interface OAI.

Lígia Arruda Café (professora da UFSC) apresentou padrões de funcionamento e padrões de metadados com características de acessibilidade, re-usabilidade, interoperabilidade, portabilidade e durabilidade. Descreveu os repositórios Ariadne, Edna, Merlot, Wisconsin e Universia, usando diferentes tipos de padrões Dublin Core, LOM, SCORM e ISO-19788-2.

Luiz Atilio Vicentini (Biblioteca da Universidade de Campinas) apresentou o processo de digitalização das teses e dissertações da instituição. Mostrou as estatísticas de acesso e download.

Marcos Sunye (professor da Universidade Federal do Paraná) apresentou o trabalho desenvolvido no Centro de Computação Científica e Software Livre que estuda Enc. Bibli: R. Eletr. Bibliotecon. Ci. Inf., ISSN 1518-2924, Florianópolis, v. 15, n. 29, p.209-211, 2010. 
alternativas de segurança para a grande quantidade de informação e necessidade de preservação por décadas, enquanto a mídia dura poucos anos. Também destacou os problemas advindos da rápida obsolescência da mídia e do hardware.

Maria Carmen Romcy de Carvalho (Biblioteca da Universidade Católica de Brasília) descreveu o processo de criação do Repositório da universidade, com destaque para o plano de implantação, análise das dificuldades e projeção das ações futuras.

Marisa Bräscher (professora da UnB) apresentou a definição dos termos associados, Organização da Informação e Organização do Conhecimento. Descreveu os modelos de Arquitetura da Informação e exemplos de organização de vários repositórios.

Miguel Angel Márdero Arellano (Instituto Brasileiro de Ciência e Tecnologia) defendeu o Acesso Livre como um elemento de inclusão. Descreveu detalhadamente os requisitos e funcionalidades de um repositório, bem como os requisitos para garantir a preservação digital e a confiabilidade deste repositório.

Satyro Oliveira (4S Informática) mostrou o trabalho da empresa na preservação e gerenciamento de arquivos de vídeos. Longevidade, segurança e recuperação são aspectos essenciais, assim como a migração de diferentes objetos de informação entre mídias de fornecedores diferentes.

Chama a atenção a abrangência dos temas e a atualidade das apresentações, justificando a organização de eventos, pois permitem discussões com um grau de liberdade que se mostra especialmente pertinente em novas áreas de estudo e atuação da ciência da informação e áreas correlatas. 